\title{
O Desenvolvimento de Culturas Tolerantes ao Herbicida Diclorofenoxiacetato: REVISÃo DE LITERATURA ${ }^{1}$
}

\author{
The Development of Dichlorophenoxyacetate Herbicide Tolerant Crops: Literature Review
}

\author{
QUEIROZ, A.R.S. ${ }^{2}$ e VIDAL, R.A. ${ }^{2}$
}

\begin{abstract}
RESUMO - O composto diclorofenoxiacetato (2,4-D) foi o primeiro herbicida orgânico, sistêmico, seletivo e de aplicação em pós-emergência desenvolvido no mundo. Juntamente com a revolução verde, ele contribuiu para elevar a produção dos cereais nas décadas posteriores a 1950. Esse produto é uma auxina sintética que pode ser utilizada como regulador do crescimento vegetal ou, ainda, como herbicida para o controle de espécies daninhas dicotiledôneas. Várias espécies infestantes dicotiledôneas que apresentam dificuldade de controle com outros herbicidas são suscetíveis ao 2,4-D. Contudo, a utilização desse herbicida fica restrita pela falta de seletividade em algumas culturas agrícolas. Nas últimas décadas, a descoberta de genes relacionados à tolerância ao 2,4-D em bactérias encontradas no solo e a sua transferência para culturas possibilitaram o desenvolvimento de linhagens tolerantes ao produto. Os objetivos desta revisão de literatura foram apresentar os genes e a atividade das enzimas responsáveis pela tolerância ao herbicida 2,4-D; ilustrar os mecanismos envolvidos na seletividade ao 2,4-D e a outros herbicidas; e equacionar algumas implicações para o manejo de plantas daninhas. O primeiro gene de tolerância ao 2,4-D descoberto foi o tfdA, encontrado no plasmídeo pJP4 da bactéria Cupriavidus necator. Este gene codifica a enzima 2,4-D/oxoglutarato dioxigenase, a qual realiza a conversão do 2,4-D em 2,4-diclorofenol e glioxilato. No final da década de 1980 , foi realizada a primeira inserção do gene $t f d A$ em plantas de Nicotiana tabacum, mediada por Agrobacterium tumefaciens. Isso conferiu tolerância de plantas de fumo ao 2,4-D. Resultados similares foram obtidos com inserções posteriores deste gene em plantas de Gossypium hirsutum, Brassica juncea e Vitis vinifera. Com a continuidade dos estudos de bactérias de solo, identificaram-se outros dois genes: o gene $r d p A$ de Sphingobium herbicidivorans MH, que codifica a enzima ariloxialcanoato dioxigenase-1 (AAD-1); e o sdpA de Delftia acidovorans MC1, que codifica a enzima ariloxialcanoato dioxigenase-1(AAD-12). Essas duas enzimas são similares, mas têm cinética enzimática diferenciada e são capazes de degradar o 2,4-D e outros herbicidas. A enzima AAD-1 degrada o 2,4-D e, surpreendentemente, alguns herbicidas inibidores da acetil-CoA carboxilase (ACCase) do grupo dos ariloxifenoxipropionatos (FOPs). A enzima AAD-12 apresenta alta afinidade de ligação com os auxínicos 2,4-D, MCPA, triclopyr e fluroxypyr. Atualmente os genes que codificam estas enzimas estão sendo utilizados para o desenvolvimento de cultivares de soja, algodão e milho tolerantes ao 2,4-D e FOPs. Plantas de soja com o transgene sdpA se mostraram tolerantes ao 2,4-D. Plantas de milho contendo o gene $r d p A$ também são tolerantes aos herbicidas FOPs. Trabalhos realizados com as espécies daninhas Conyza bonariensis, Conyza canadensis e Amaranthus palmeri resistentes ao herbicida glyphosate têm mostrado controle adequado com o 2,4-D. Portanto, os genes $s d p A$ e $r d p A$ são bons candidatos no desenvolvimento de culturas tolerantes ao 2,4-D e deverão ampliar as opções de controle de espécies daninhas de dificil manejo com outros herbicidas.
\end{abstract}

Palavras-chave: 2,4-D, plantas daninhas, resistência aos herbicidas.

ABSTRACT - The compound dichlorophenoxyacetate $(2,4-D)$ was the first organic, systemic, selective herbicide, and for post-emergence application to be developed in the world. Along with the green revolution, this herbicide has helped to increase the cereal production on the decades after 1950. This product is a synthetic auxin that can be used as a plant growth regulator or as an herbicide for

Recebido para publicação em 10.5.2014 e aprovado em 15.5.2014.

Universidade Federal do Rio Grande do Sul, Porto Alegre-RS, Brasil, <ribas.vidal@gmail.com>;

Planta Daninha, Viçosa-MG, v. 32, n. 3, p. 649-654, 2014 
the control of broad-leaved weeds. Several broad-leaved weed species that have proved difficult to control with other herbicides are susceptible to 2,4-D. However, the use of this herbicide is restricted due to the lack of selectivity in certain crops. In recent decades, the discovery of genes related to 2,4-D tolerance in soil bacteria and its transfer to crops enabled the development of tolerance to the herbicide. The objectives of this literature review are to describe the enzymes and genes responsible for 2,4-D tolerance; to illustrate the mechanisms involved in the selectivity to 2,4-D and to other herbicides; and to analyze some of the implications for weed management. The first 2,4-D tolerance gene to be discovered was tfdA, which was found in the plasmid pJP4 from the bacterium Cupriavidus necator. This gene encodes for the 2,4 D/oxoglutarate dioxygenase enzyme, which catalyzes the conversion of 2,4-D to 2,4 dichlorophenol and glyoxylate. During the late 1980s occurred the first insertion of the $t f d A$ gene in plants of Nicotiana tabacum via Agrobacterium tumefaciens. This conferred tolerance of tobacco plants to 2,4-D. Similar results were obtained with insertion of this gene into plants from several crops, such as Gossypium hirsutum, Vitis vinifera, and Brassica juncea. Studies on soil bacteria have identified two other genes, the rdpA gene from Sphingobium herbicidivorans $M H$, which encodes the enzyme ariloxyalkanoate-dioxygenase- 1 $(A A D-1)$; and the sdpA gene from Delftia acidovorans MC1, which encodes the enzyme ariloxyalkanoate-dioxygenase-12 (AAD-12). These two enzymes are similar, but have different enzyme kinetics and are able to degrade 2,4-D and other herbicides. The $A A D-1$ enzyme degrades 2,4-D and, surprisingly, the ariloxyphenoxypropionate (AAPP) herbicides, which inhibit acetyl-CoA carboxylase (ACCase). The AAD-12 enzyme has a high binding affinity with the auxins 2,4-D, MCPA, triclopyr, fluroxypyr. Currently, the genes encoding these enzymes are being used for the development of soybean, cotton, and corn tolerant to 2,4-D and AAPP. Soybean plants with the gene sdpA are highly tolerant to 2,4-D. Corn plants containing the gene rdpA are also tolerant to AAPP. Work carried out with the glyphosate resistant weeds Conyza bonariensis, Conyza canadensis, and Amaranthus palmeri have shown adequate control with 2,4-D. Therefore, the sdpA and $r d p A$ genes are good candidates to develop 2,4-D tolerant crops and should expand the options to control weeds resistant to other herbicides.

Keywords: 2,4-D, weeds, herbicide resistance.

\section{INTRODUÇÃO}

O composto diclorofenoxiacetato $(2,4-\mathrm{D})$ foi o primeiro herbicida orgânico, seletivo e de aplicação em pós-emergência desenvolvido no mundo. Juntamente com a revolução verde, ele contribuiu para a elevação da produção dos cereais nas décadas posteriores a 1950 (Sterling \& Hall, 1997). Esse produto é uma auxina sintética que pode ser utilizada como regulador de crescimento vegetal ou como herbicida para o controle de espécies daninhas dicotiledôneas (Mortensen et al., 2012). O principal mecanismo apontado para ação desse herbicida nas plantas é a estimulação da produção de ácido1-carboxílico-1-aminociclopropano (ACC) sintase, enzima responsável pela biossintese do hormônio etileno. O aumento da concentração deste hormônio acelera a senescência das plantas e, ao final, a morte (Grossmann, 2010). Entre as auxinas sintéticas existem quatro grupos químicos: fenoxialcanoatos (2,4-D, 2,4-DB, MCPA e
MCPB), benzoatos (dicamba), piridinacarboxilatos (clopyralid, fluroxipyr, picloran e triclopyr) e quinolinocarboxilatos (quinclorac e quinmerac) (Di Meo, 2012).

Várias espécies infestantes dicotiledôneas que apresentam dificuldade de controle com outros herbicidas são suscetiveis ao 2,4-D (Mortensen et al., 2012; Heap, 2014). Contudo, a utilização deste herbicida fica restrita pela falta de seletividade em algumas culturas agrícolas. Nas últimas décadas, a descoberta de genes relacionados à tolerância ao 2,4-D em bactérias encontradas no solo e sua transferência para culturas possibilitaram o desenvolvimento de culturas tolerantes ao produto (Craigmyle et al., 2013; Griffin et al., 2013). Surpreendentemente, algumas enzimas codificadas por esses genes são capazes de degradar outros herbicidas auxinicos e até mesmo herbicidas de outras classes (Wright et al., 2010). Os objetivos desta revisão foram apresentar os genes e a atividade das enzimas responsáveis pela tolerância ao herbicida 


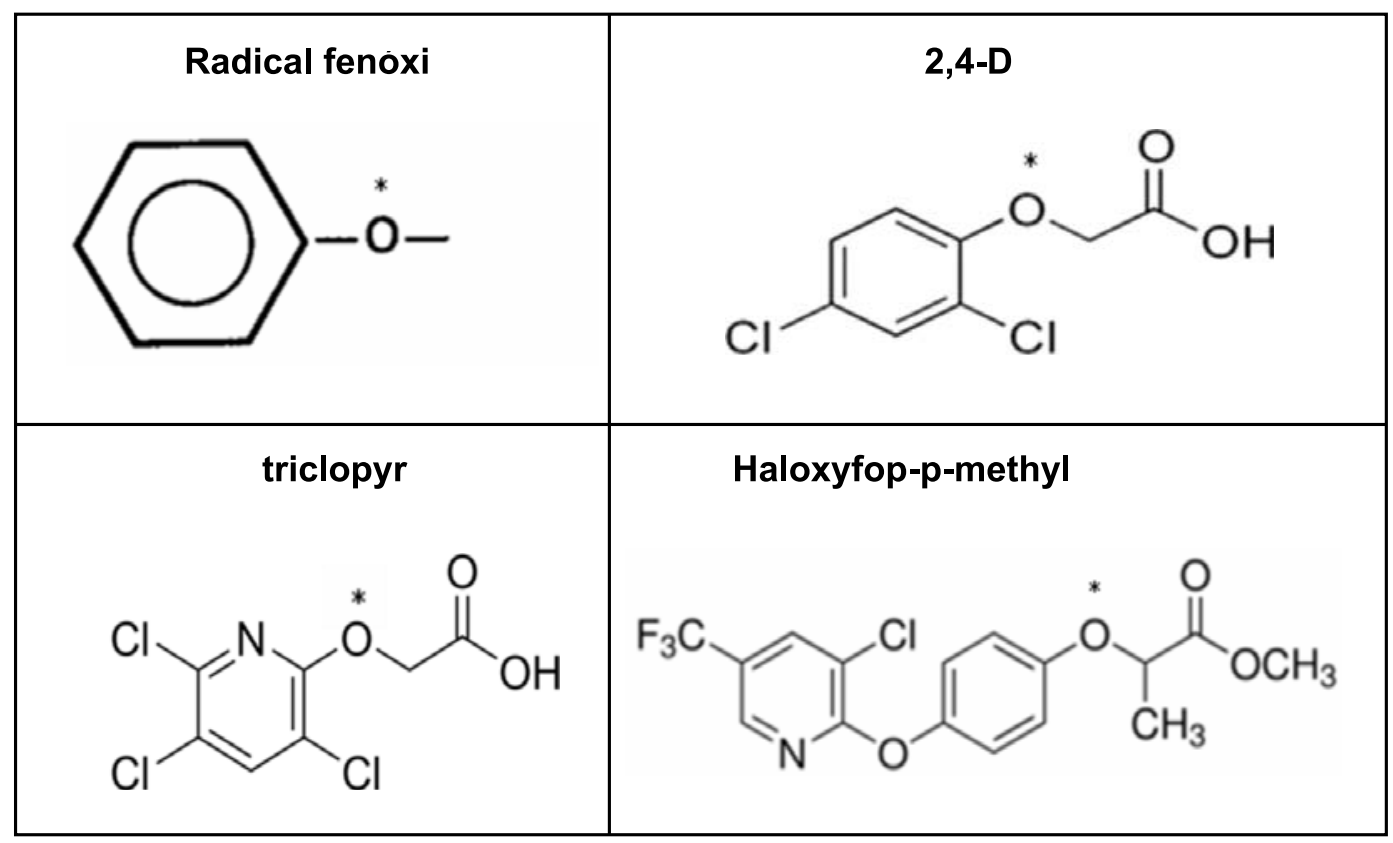

Figura 1 - Estrutura química dos herbicidas auxínicos 2,4-D e triclopyr em comparação com o herbicida inibidor da ACCase haloxyfop-p-methyl. O asterisco denota a região de hidroxilação das moléculas pela ação das enzimas ariloxialcanoato dioxigenases (AADs).

2,4-D; ilustrar os mecanismos envolvidos na seletividade ao 2,4-D e a outros herbicidas; e equacionar algumas implicações para o manejo de plantas daninhas.

\section{Descoberta do gene e da enzima de detoxificação do 2,4-D}

No início da década de 1980 , era de conhecimento do meio científico (Fulthorpe et al., 1996; Kamagata et al., 1997) a capacidade de algumas estirpes de bactérias do solo de degradarem o herbicida 2,4-D. No entanto, não se tinha o conhecimento do gene específico que conferia essa capacidade. Com o decorrer do tempo, o gene responsável pela primeira rota de degradação do 2,4-D foi isolado a partir do pJP4, um plasmídeo encontrado na bactéria Alcaligenes eutrophus, atualmente denominada Cupriavidus necator (Bayley et al., 1992). O gene $t f d A$ codifica a enzima 2,4-D dioxigenase, a qual catalisa a conversão do 2,4-D em 2,4-diclorofenol (2,4-DCP) e glioxilato, enquanto simultaneamente oxida a $\alpha$-cetoglutarato para formar $\mathrm{CO}_{2}$ e succinato (Itoh et al., 2002). Essas dioxigenases são enzimas que utilizam o oxigênio e $\alpha$-cetoglutarato como substratos na catálise de uma ampla gama de processos oxidativos, como hidroxilações, epoxidações, desaturações e formação de anéis benzeno em bactérias e plantas (Müller et al., 2006).

A descoberta do gene de detoxificação do 2,4-D possibilitou entender a rota de biodegradação bacteriana desse herbicida. Por meio de técnicas de transgenia, foi possivel realizar a transferência desse gene para espécies cultivadas, tornando-as tolerantes ao herbicida 2,4-D (Lyon et al., 1989; Lyon et al., 1993; Bisht et al., 2004; Mulwa et al., 2007). Por exemplo, a inserção do gene $\mathrm{t} f d A$ em plantas de Nicotiana tabacum (mediada por Agrobacterium tumefaciens) permitiu a sobrevivência de plantas após a utilização do 2,4-D (Lyon et al., 1989). Plantas de Gossypium hirsutum transformadas com esse gene também apresentaram tolerância ao herbicida (Lyon et al., 1993). Similarmente, plantas de Brassica juncea contendo o gene tfdA apresentaram elevada resistência ao 2,4-D (Bisht et al., 2004). Em outro estudo, regeneraramse calos de Vitis vinifera cv. Chancellor contendo o gene $t f d A$ a partir de meio de cultura e, posteriormente, constatou-se tolerância das plantas ao 2,4-D (Mulwa et al., 2007). 


\section{Novos genes e enzimas na degradação do 2,4-D e outros produtos}

Os genes rdpA ou aad-1 de Sphingobium herbicidivorans MH e sdpA ou aad-12 de Delftia acidovorans MC1 (ambas as bactérias encontradas no solo) produzem enzimas com $28 \mathrm{e}$ $31 \%$, respectivamente, de homologia de aminoácidos com o produto do gene $t f d A$. Ou seja, todas as enzimas possuem sequências de aminoácidos com elevado grau de similaridade (Wright et al., 2010).

Convém esclarecer que a nomenclatura desses genes é dada em função da especificidade de atuação das enzimas em relação às formas enantioméricas dos herbicidas fenoxipropionatos e fenoxiacetatos. Assim, o gene $r d p A$ codifica a enzima denominada (R)fenoxipropionato/ $\alpha$-cetoglutarato dioxigenase (RdpA), a qual possui elevada especificidade de atuação sobre a configuração $\mathrm{R}$ dos fenoxipropionatos e fraca especificidade sobre derivados de 2,4-D. Alternativamente, a enzima gerada pelo gene $s d p A$ é denominada (S)-fenoxipropionato/ $\alpha$-cetoglutarato dioxigenase ( $\mathrm{SdpA})$ e possui elevada especificidade pela configuração S dos fenoxipropionatos e por 2,4-D e seus derivados (Westendorf et al., 2003; Müller, 2007).

Essas enzimas também são conhecidas como ariloxialcanoato dioxigenases (AADs). O gene $r d p A$, por exemplo, é o responsável pela sintese da enzima AAD-1, que tem a capacidade de degradar os herbicidas dos grupos dos ariloxifenoxipropionatos (FOPs), inibidores da acetil-CoA carboxilase (ACCase) (Wright et al., 2009). Todavia, o gene $s d p A$ codifica a enzima AAD-12, a qual consegue detoxificar compostos auxínicos, como 2,4-D, MCPA, triclopyr e fluroxipyr.

Uma característica em comum entre os herbicidas auxinicos e ariloxifenoxipropionatos é a presença do radical fenoxi. Assim, teoriza-se que nesta região ocorre a hidroxilação pelas enzimas AADs (Figura 1). Atualmente esses genes estão sendo usados para o desenvolvimento de cultivares de soja, algodão e milho tolerantes ao 2,4-d e ariloxifenoxipropionatos (Wright et al., 2010; Griffin et al., 2013; Herman et al., 2013; Hoffman et al., 2013; Lepping et al., 2013). Plantas de soja com o transgene $s d p A$ se mostraram altamente tolerantes ao 2,4-D (Wright et al., 2010). A inserção do gene $r d p A$ em plantas de milho possibilitou a tolerância aos herbicidas ariloxifenopropionatos, de forma que as plantas transgênicas sobreviveram às doses de $0,28 \mathrm{~kg} \mathrm{ha}^{-1}$ de cyhalofop e $0,56 \mathrm{~kg} \mathrm{ha}^{-1} \mathrm{de}$ quizalofop (Wright et al., 2010). Plantas de Nicotiana tabacum contendo os transgenes rdpA e $s d p A$ apresentaram elevada tolerância ao 2,4-D, com ausência de danos mesmo em doses muito superiores às utilizadas em campo (Hoffman et al., 2013).

Estudo realizado com plantas de soja contendo o transgene $s d p A$ demonstrou que a enzima AAD-12 não possui afinidade catalitica com a auxina natural AIA (ácido indolacético), de forma que não representa riscos para o metabolismo das plantas (Griffin et al., 2013). De fato, outras pesquisas que compararam plantas não transformadas com as trasformadas não constataram alterações bioquímicas em plantas de algodão (Herman et al., 2013), milho (Lundry et al., 2013) ou soja (Lepping et al., 2013).

\section{Implicações no manejo de plantas daninhas}

O uso de plantas cultivadas contendo genes de tolerância ao 2,4-D irá gerar mudanças na forma como o herbicida é utilizado. Alguns trabalhos demonstram a eficiência do 2,4-D no controle de plantas daninhas de dificil manejo com outros herbicidas, como, por exemplo, Conyza bonariensis, Conyza canadensis e Amaranthus palmeri resistentes ao glyphosate (Soares et al., 2012; Kruger et al., 2010). Entretanto, em algumas espécies, apenas o uso do 2,4-D pode não ser suficiente para controlar todos os indivíduos. Em experimento realizado com plantas de Amaranthus palmeri resistentes ao herbicida glyphosate, foi constatado que elevado controle delas apenas era alcançado com o uso do 2,4-D mais o herbicida glufosinate (Merchant et al., 2013). Esse fato é auspicioso, pois estimulará a associação de 2,4-D com outros herbicidas, de forma a minimizar a pressão de seleção do produto, e, assim, pode prevenir a evolução de casos de plantas daninhas com resistência ao produto. A utilização de herbicidas de 
diferentes mecanismos de ação é aconselhada e necessária para a manutenção em longo prazo da eficiência do manejo de daninhas (Vidal et al., 2010).

\section{AGRADECIMENTOS}

Ao CNPQ e à CAPES, pelo apoio aos pesquisadores. Agradecemos às sugestões apresentadas pelos professores M.M. Trezzi (UTFPR) e N.D. Kruse (UFSM).

\section{LITERATURA CITADA}

BAYLEY, C. et al. Engineering 2,4-D resistance into cotton. Theor. Appl. Genetics, v. 83, n. 5, p. 645-649, 1992.

BISHT, N. C. et al. Development of 2,4-d-resistant transgenics in Indian oilseed mustard (Brassica juncea). Curr. Sci., v. 87, n. 3, p. 367-370, 2004.

CRAIGMYLE, B. D.; ELLIS, J. M.; BRADLEY, K. W. Influence of weed height and glufosinate plus 2,4-d combinations on weed control in soybean with resistance to 2,4-d. Weed Technol., v. 27, n. 2, p. 271-280, 2013.

DI MEO, N. L. Understanding the inheritance and mechanism of auxinic herbicide resistance in wild radish (Raphanus raphanistrum L.). $118 \mathrm{f}$. Thesis (Master of Science in Environmental Biology) - University of Guelph, Guelph, 2012.

FULTHORPE, R. R.; RHODES, A. N.; TIEDJE, J. M. Pristine soils mineralize 3-chlorobenzoate and 2,4dichlorophenoxyacetate via different microbial populations. Appl. Environ. Microbiol., v. 62, n. 4, p. 1159-1166, 1996.

GRIFFIN, S. L. et al. Characterization of aryloxyalkanoate dioxygenase-12, a nonheme fe(ii)/á-ketoglutarate-dependent dioxygenase, expressed in transgenic soybean and Pseudomonas fluorescens. J. Agric. Food Chem., v. 61, n. 27, p. 6589-6596, 2013.

GROSSMANN, K. Auxin herbicides: current status of mechanism and mode of action. Pest Manag. Sci., v. 66, n. 2, p. 113-120, 2010.

HEAP, I. The international survey of herbicide resistant weeds. Disponível em: <www.weedscience.org > . Acesso em: 26 jan. 2014.

HERMAN, R. A. et al. Compositional safety of herbicidetolerant DAS-81910-7 cotton. J. Agric. Food Chem., v. 61, n. 47, p. 11683-11692, 2013.

HOFFMAN, T. et al. Methods of improving the yield of 2,4d resistant crop plants. U.S. Patent 20.130.260.995, Dow Agrosciences Llc, Indiana: 2013.
ITOH, K. et al. tfdA-Like genes in 2,4-dichlorophenoxyacetic acid-degrading bacteria belonging to the BradyrhizobiumAgromonas-Nitrobacter-Afipia cluster in á-Proteobacteria. Appl. Environ. Microbiol., v. 68, n. 7, p. 3449-3454, 2002.

KAMAGATA, Y. et al. Pristine environments harbor a new group of oligotrophic 2,4-dichlorophenoxyacetic aciddegrading bacteria. Appl. Environ. Microbiol., v. 63, n. 6, p. 2266-2272, 1997.

KRUGER, G. R. et al. Control of horseweed (Conyza canadensis) with growth regulator herbicides. Weed Technol., v. 24, n. 4, p. 425-429, 2010.

LEPPING, M. D.; HERMAN, R. A.; POTTS, B. L. Compositional equivalence of DAS-444Ø6 6 (AAD-12+ 2mEPSPS + PAT) herbicide-tolerant soybean and nontransgenic soybean. J. Agric. Food Chem., v. 61, n. 46, p. 11180-11190, 2013.

LUNDRY, D. R. et al. Composition of grain and forage from insect-protected and herbicide-tolerant corn, MON 89034 x TC1507 x MON 88017 x DAS-59122-7 (Smartstax), is equivalent to that of conventional corn (Zea mays L.). J. Agric. Food Chem., v. 61, n. 8, p. 1991-1998, 2013.

LYON, B. R. et al. Expression of a bacterial gene in transgenic tobacco plants confers resistance to the herbicide 2,4dichlorophenoxyacetic acid. Plant Molec. Biol., v. 13, n. 5, p. 533-540, 1989.

LYON, B. R. et al. Cotton plants transformed with a bacterial degradation gene are protected from accidental spray drift damage by the herbicide 2,4-dichlorophenoxyacetic acid. Transg. Res., v. 2, n. 3, p. 162-169, 1993.

MERCHANT, R. M. et al. Weed response to 2,4-d, 2,4-db, and dicamba applied alone or with glufosinate. J. Cotton Sci., v. 17, n. 3, p. 212-218, 2013.

MORTENSEN, D. A. et al. Navigating a critical juncture for sustainable weed management. Bioscience, v. 62, n. 1, p. 75-84, 2012.

MÜLLER, T. A. et al. Purification and characterization of two enantioselective alpha-ketoglutarate-dependent dioxygenases, $R d p A$ and $S d p A$, from Sphingomonas herbicidovorans MH. Appl. Environ. Microbiol., v. 72, n. 7, p. 4853-4861, 2006.

MÜLLER, R. H. Activity and reaction mechanism of the initial enzymatic step specifying the microbial degradation of 2,4-dichlorophenoxyacetate. Eng. Life Sci., v. 7, n. 4, p. 311-321, 2007.

MULWA, R. M. S. et al. Agrobacterium-mediated transformation and regeneration of transgenic' Chancellor' wine grape plants expressing the $t f d A$ gene. Vitis, v. 46, n. 3, p. 110-115, 2007. 
SOARES, D. J. et al. Control of glyphosate resistant hairy fleabane (Conyza bonariensis) with dicamba and 2,4-d. Planta Daninha, v. 30, n. 2, p. 401-406, 2012.

STERLING, T. M.; HALL, J. C. Natural auxins and the auxinic herbicides. In: ROE, R. M.; BURTON, J. D.; KUHR, R. J. Herbicide activity: toxicology, biochemistry and molecular biology. Netherlands: IOS Press, 1997. 205 p.

VIDAL, R. A. et al. Herbicide resistant weed management using sensitivity analysis of the weed population growth curve. Pesticidas: R. Ecotoxicol. Meio Amb., v. 20, n. 1, p. 7-16, 2010.
WESTENDORF, A.; MÜLLER, R. H.; BABEL, W. Purification and characterisation of the enantiospecific dioxygenases from Delftia acidovorans MCI initiating the degradation of phenoxypropionate and phenoxyacetate herbicides. Acta Biotechnol., v. 23, n. 1, p. 3-17, 2003.

WRIGHT, T. R. et al. Novel herbicide resistance genes. U.S. Patent 20.090.093.366, Dow Agrosciences Llc, Indiana: 2009.

WRIGHT, T. R. et al. Robust crop resistance to broadleaf and grass herbicides provided by aryloxyalkanoate dioxygenase transgenes. Proc. Nat. Acad. Sci.e USA, v. 107, n. 47, p. 20240-20245, 2010. 